\title{
Competence-based Education and the Limitations of Critique
}

Richard Edwards, University of Stirling, UK

\begin{abstract}
Drawing upon the work of Foucault and Latour, this article reflects upon 25 years of critique of competence-based education and its continuing strength as a way of framing education and training. Using an example from England, it rehearses the argument from Foucault that, despite its student-centred discourse, competence-based education can be positioned as one of the disciplining techniques in modern societies. However, beyond the research community, such critiques have had little impact. The article seeks to explore this by drawing upon Latour's argument that conventional forms of critique have run out of steam. This indicates the need for new forms of educational critique as a means of having impact on policy and practice. The article is theoretically driven and exploratory.
\end{abstract}

\section{Introduction}

In 1994 Robin Usher and I published an article entitled 'Disciplining the subject: the power of competence' (Edwards and Usher 1994). It was part of a wave of critical pieces on the emergence of competency-based approaches to vocational education. Such pieces were widely cited and debates were ongoing - for a while. However, like waves on the beach, the initial crash and surge of critical energy eventually waned and competency-based education and training continued its serene development. Ripples of critique have continued over the decades, but they have had limited impact. It seems strange to reflect back on that period from 2016, where discussion of the values and effects of competence-based education seem to have been re-ignited or are being repeated in certain quarters. 
In this article, I propose to do two things. First, I wish to revisit the argument Robin and I put forward in 1994. Largely drawn from aspects of the work of Foucault, I want to propose that the central argument is still theoretically valid. However, I now want to acknowledge that such analysis is limited as a practical form of critique. In the second part of the article, I therefore wish to reflect on the failures of such conventional forms of academic critique, of which I take the discussions from the 1990s to be largely an example, and suggest the need for different forms of critical intervention. This draws upon Latour's (2004) argument that sociological critique has run out of steam and the work I have done with Tara Fenwick to explore the implications of that position for educational researchers (Edwards and Fenwick 2015).

\section{Competence and critique}

A number of positions critical of the introduction of competence-based education and training were discernible in the 1990s. First, there were those who questioned the notion of competence as an adequate conceptualisation of human practices. For instance, Ashworth and Saxton (1990) argued that the notion of competence ignored wider human qualities and notions of knowledge and understanding which are integral to education. This related to criticisms that competences reflected a revitalised behaviourism (Field 1990). Second, there were those who doubted that the competence-based system could be delivered at a cost and standard of quality that would gain credibility (e.g. Raggatt 1991). Third, there were those who argued that the aim of increasing the pool of skilled labour through increasing competence would not be achieved, as the competences developed remain too narrowly conceived (e.g. Hyland 1992). 
Robin Usher and I were interested in the discursive work competence-based education was doing and how it related to Foucault's (1979) analysis of disciplinary power in modern institutions. In particular, we were interested in the ways discourses of competence could be argued to work in disciplining people through a process of self-discipline to become particular forms of subjectivity, both active subject and docile bodies. This critique was part of a wave of educational research informed by the work of Foucault at the time. Here competency-based education was positioned as a key component of a power-knowledge formation, a set of discursive and material practices, which were trying to regulate and shape subjectivities in particular ways. This was argued to be part of a strategy of governing at a distance, a means of trying to produce consent in the population without the need for explicit oppression and force. As part of a power-knowledge formation, competency-based education was argued to be a discourse of and about learning which, although based on the disciplinary knowledge of the behavioural sciences, had a narrowly confined and particular view of knowledge that excluded alternative perspectives.

The Foucualdian theoretical framing to inform this argument at the time has become a common place basis for forms of educational critique for almost 30 years. For Foucault, power and knowledge, rather than being opposites - the exercise of power being a constraint on knowledge - are inseparable from one another. He refers to power and knowledge as being correlative, always found together in 'regimes of truth', the knowledge practices and discourses through which power is enacted. Knowledge does not represent the truth of what is, but rather enacts what is taken to be true. Individuals are regulated and governance secured through power-knowledge formations constituted by networks of discursive and material practices. Here then, power does not operate through coercion and repression. Indeed such acts could be seen as examples of the failure of power. Power is exercised 
through 'knowledgeable' discourses and practices, which observe, measure, categorise, divide and regulate.

In a sense, all practices are 'knowledgeable', but only those with a disciplinary validated truth are power-knowledge formations. Power-knowledge is integral to certain practices and it is through these that individuals become 'subjects' and 'subject'. The discourses of powerknowledge formations produce subjects who are 'subject' to certain forms of ordering and regulation. Through disciplinary practices, knowledge and the ordering of behaviour coemerge. Discipline, in both a power and a knowledge sense, is manifest in the orderings of the institutions of modern societies - the asylum, the prison, the hospital, and. of course, the institutions of education and training. Disciplinary power means there can be no such thing as an asocial or pre-social autonomous human subject, To be a human subject is to be discursively constituted and subject to disciplinary power. There is nowhere where subjects are not already situated within discourses or where they can be completely untouched by power-knowledge formations. Discipline operates 'where power reaches into the very grain of individuals, touches their bodies and inserts itself into their actions and attitudes, their discourses, learning processes and everyday lives' (Foucault 1980 p39).

In reformulating the relationship between power and knowledge, power itself has to be reconceptualised. Foucault argues that it should not be seen simply in a negative way, as prohibition but rather as also creative and active. Power through knowledge 'brings forth' active subjects who better 'understand' their own subjectivity and in this very process subject themselves. 
We must cease once and for all to describe the effects of power in negative terms: it 'excludes', it 'represses' it 'censors', it abstracts' it 'masks', it 'conceals' In fact, power produces; it produces reality; it produces domains of objects and rituals of truth. The individual and the knowledge that may be gained of him [sic] belong to this production.

(Foucault 1979 p194)

In other words, in order to be regulated, the individual first has to be constituted as an active subject through a process of observation/surveillance, the criteria and methods of which are provided by disciplinary knowledge. The individual is thus both an object of power and a subject through which power is exercised.

Foucault focused primarily on the operation of power-knowledge in prisons, asylums, and on sexuality. However, it is clear that the institutions of education and training are also perceived as important sites of regulation.

The chief function of the disciplinary power is to 'train', rather than to select and to levy; or, no doubt, to train in order to levy and select all the more... Instead of bending all its subjects into a single uniform mass, it separates, analyses, differentiates, carries its procedures of decomposition to the point of necessary and sufficient single units... The exercise of discipline presupposes a mechanism that coerces by means of observation...

(Foucault 1979 p170).

It was in the disciplinary power to train that there emerged an explicit relationship between Focuauldian analysis and a possible critique of competence-based education. Disciplinary 
power functions through the practice of surveillance. Subjects are constructed in their individuality and subjectivity by a process of itemisation and atomisation as they become subject to the categorisations generated to 'understand' and 'learn' more about them and their actions. These categories are embodied in dossiers, files and records of various kinds. As the need to regulate increases, so does the need to know more about individuals. Surveillance becomes ever more pervasive and intrusive yet without appearing to be oppressive.

In competence-based education and training in 1990's UK, this process could be discerned in the increased emphasis on learning outcomes, the scope and impact of assessment procedures, evaluation and appraisal mechanisms and records of achievement. The process of continuous assessment and credit accumulation was identifiable as part of a continuously expanding surveillance of the learner, and a continuous disciplining through the goal of competent behaviour at every stage of the process. There is no space for independence of thought or action along the way if one wishes to achieve competence and find a space in the workforce; and with the presence of structural unemployment finding such a space becomes increasingly vital for many.

Increased surveillance does not necessarily mean the direct gaze of the tutor/lecturer/assessor. The latter is certainly necessary at the point of assessment, to judge, to tick off (for competence or incompetence), to log. Surveillance is inscribed in the very list of competences and performance criteria that are put before learners as the desirable goal of the learning process; it is implicit in those criteria and made manifest when assessment takes place. Through their inscription in the National Vocational Qualifications (NVQ) system persons become a bundle of competences; in effect they become their NVQs. However, because the performance criteria are public, they appear even more as 'objective' forms of 
measurement from which the exercise of power is drained. In fact, they appear to be empowering precisely because they are publicly available to learners. Learners know what they have to demonstrate and can assess themselves as they move towards that goal. In operating within a discourse of competence, learners themselves become the subjects of their own surveillance; they are able to sit in judgement upon themselves. In the discourse and practices of competence based qualifications, they are disciplined through self-discipline. As Foucault points out, A relation of surveillance, defined and regulated, is inscribed at the heart of the practice of teaching, not as an additional or adjacent part, but as a mechanism that is inherent to it and which increases its efficiency.

(Foucault 1979 p176).

He is making this point in relation to all teaching, but we were particularly concerned with the forms it was taking in the development of competence-based education, in which teachers and trainers become both active in and subject to the disciplinary process of individual measurement and assessment. The power of normalisation imposes homogeneity; but it individualises and personalises by making it possible to measure gaps, to determine levels, to fix specialities and to render the differences useful by fitting them one to another. The significance of a norm is that it works by excluding; it defines a standard and criteria of judgement thus identifying all those who do not meet the standard. In this way, a picture is provided of where a person is 'competent' and correspondingly where s/he is lacking or deficient. The moves to norm referenced assessment in competence-based approaches clearly seemed to illustrate an aspect of the spread of disciplinary power in modern social orders. 
Persons become subjects by being classified in terms of their capacity to meet the norms. In effect, they become their capacities and it is through these capacities, or the lack of them that they become 'objects' of surveillance and regulation. This process is not neutral, but the significance of normalisation is precisely that it appears to be neutral; a person is measured against independent standards and norms. In its 'objectivity' it appears to be simply a neutral procedure for ascertaining inherent 'natural' capacities. Assessment is therefore against 'objective' criteria which subjects have to accept (because not to do so would be irrational and deviant) as saying something about what they are as persons. But, as we have noted before in discussing disciplinary power, assessment has a double effect insofar as it is a process of objectification, of persons becoming objects to be classified and measured and of subjectification, where they become subjects who 'learn' the truth about themselves.

How then does this analysis relate to competence-based education and training explicitly? To provide an answer to that question requires firstly to explore the discourse of competence, which can then be related to ideas of surveillance, discipline and power-knowledge. The argument is that the discourse of competence enacts a technology of power within the education and training system as part of wider changes and does so in ways which position individuals as responsible for their own situation in the labour market.

Historically, looking back in the specific context of the UK, in 1988 the then National Council for Vocational Qualifications (NCVQ) published its criteria and related guidance (1988). In this document competence was defined as 'the ability to perform a range of workrelated activities, and the skills, knowledge and understanding which underpin such performance in employment' (NCVQ $1988 \mathrm{p} 8$ ). The key here is that it is not simply performance, what a person can do, which is to be judged. It is also apparently the skills, 
knowledge and understanding which go into that performance. This immediately raises a tension within the whole NVQ framework and one which spawned much debate (e.g. Ashworth and Saxton 1990, Wolf and Mitchell 1991).

On the one hand, if the skills, knowledge and understanding which underpin a performance are to be assessed in addition to the performance itself, there is the obvious danger that the assessment procedure becomes overloaded and cumbersome. This led to arguments over whether the underpinning abilities can be implied from successful performance across a range of situations and how far the separate assessment of knowledge and understanding was consistent with the functional analysis approach by which competences were meant to be derived. The NCVQ stated that the requirement of the award to provide progression 'does not imply building into the requirements of an NVQ knowledge and understanding beyond the needs of the employment to which the award relates' (NCVQ 1988 p10). These arguments are given particular force, because it is the perceived failure of knowledge-based vocational qualification, in part, which led to the shift towards competence in the first place.

On the other hand, there was the argument that tying skills, knowledge and understanding too narrowly to successful performance of activities does not provide the basis for transferring skills, or the forms of critical self-awareness which give people the opportunity to respond to changes in their work environments or use discretion in their work. Flexibility may well demand the type of knowledge and understanding unrelated to immediate performance which is silenced through the process of functional analysis.

It was very noticeable that the discourse of competence marginalised knowledge and understanding unrelated to workplace performance, an exclusion which is characteristic of 
power-knowledge discourses. A discourse defines what can be said, which is based on what cannot be said, on what is marginalised, silenced and repressed. The discourse of competence attempted to make knowledge and understanding the 'unsaid', but never entirely succeeded. For one thing, a discourse is not simply a way of speaking and thinking, but a material practice which is necessarily co-implicated with the world of work. The discourse of competence and its embodiment in the National Vocational Qualifications (NVQ) framework had to 'mesh' with wider discourses of the need for a flexible workforce. NVQs were meant to be a universal framework of workplace qualifications and there clearly were many types of work where qualifications centred on pre-defined performance alone was considered unacceptable and 'inappropriate'.

Drawing upon Foucault, the argument was that the discourse of competence attempted to repress knowledge and understanding, but its efforts were continually undermined by a 'return of the repressed'. Knowledge and understanding cannot be totally and permanently repressed without subverting the whole enterprise. This is in an important sense the point of weakness in the discourse of competence - what it tries to exclude but cannot and which therefore becomes a potential although ever-present site of resistance. That was and remains a valid argument to this day.

At the time, the response to this subversion was the development of the notions of generic competences and General National Vocational Qualifications (GNVQs). However, these were developments which remained firmly located within the paradigm of competence established by the NCVQ. This approach has increasingly become embedded in the wider discourses of education and training through the emphasis more generally on outcomes and norm-referenced, standardised assessment. Their pervasiveness and power is attested by the 
seeming imperviousness to critique, part of which rests in the projection of the discourse of competence as a 'progressive', student-centred form of educational and training practice.

Returning to 1988 again:

2.3 In considering awards for accreditation as NVQs, the National Council will wish to be satisfied that...

2.3.4 the award (an NVQ) should be free from any barriers which restrict access to individuals wishing to obtain it. For example, an NVQ should be independent of:

* the mode of education and training required;

* upper or lower age limits for the assessment or award of the qualification, except where legal restraints make this necessary;

* a specified period of time to be spent in education, training or work before the award can be made.

2.3.5 awarding bodies have ensured that no overt or covert discriminatory practices in regard to gender, race or those with special needs are built into the specification or its assessment procedures.

(NCVQ 1988 p9-10)

Student-centred learning, negotiation of individual learning programmes, the accreditation of prior learning, the valuing of non-educational and training institutions as sites of learning, the need for guidance and counselling of learners; all of these were to form an essential part of the discourse of competence (see Jessup 1991).

One critique would be to dismiss this position as simply an ideological appropriation of 'progressive' ideas to mystify the regressive narrowness and vocationalism of NVQs. 
However, from a Focuauldian perspective, it is precisely through its articulation with liberal humanist ideas that discourses of competence became and remain powerful. The fact that such critiques were made illustrates that, while power might be omnipresent, it is not unidirectional. Different strategies operate in the social order at any one time and provide the basis for the breakdown of established discourses, their fracturing and rearticulation in different forms. As Foucault (1981 p101-2) argued,

Discourses are tactical elements or blocks operating in the field of force relations; there can exist different and even contradictory discourses within the same strategy; they can, on the contrary, circulate without changing their form from one strategy to another, opposing strategy.

There is thus a constant struggle to 'make sense' of a situation in order to exert power within and through it. What 'sense' is made itself manifests certain positions within the powerknowledge nexus. It is this which has to be kept in mind when examining the intermixing of discourses of competence with those of liberal humanism. The fact that it is those operating within a liberal humanist discourse who are generally most vociferous about the appropriation of 'progressive' ideas only goes to demonstrate the limits of that discourse and the relatively powerless position of those located within it.

Objections to competence on the grounds of its crude behaviourism are therefore misplaced (Field 1990). The suggestion is that competences are simply behavioural objectives in a new guise. This however is to misunderstand the nature of the discourse of competence. Competences are cast in behavioural terms but the discourse is itself not behaviourist. It is 
precisely because it is not, but rather, as we have seen, interwoven with liberal humanist discourse that it is powerful.

\section{Out of steam critique}

As we have seen, the critique of competence-based education has a long history. Yet the impact of such critique upon policy and practice has been limited if non-existent. Why is this? To explore this question we need to examine some of the wider debates that have occurred in the social sciences on the effectiveness and ineffectiveness of different forms of critique. As an illustration of this, I will draw in particular upon the work of Bruno Latour. In academic research, critique can sometimes seem to be the prerogative of the political Left, associated with the promotion of justice, democracy and equity. However, there is no inherent relationship between critique and leftist politics. The latter both assumes and enacts a politics built upon a binary of the conservative and radical, wherein the former seeks to conserve and the latter to change. A brief examination of history clearly demonstrates the inadequacy of such a view, given that many of the most effective and transformative critiques in terms of political impact can be argued to have come from the political Right in recent decades. In education, the competence-based movement can be positioned itself as part of a transformational critique of more conventional knowledge-based educational practices.

Latour is concerned that established practices of social critique do not address the practices being enacted and that it has become a form of conspiracy theory enacted from both the Left and Right. In addressing these concerns, 'the practical problem we face... is to associate the word criticism with a whole set of new positive metaphors, gestures, attitudes, knee-jerk reactions, habits of thoughts' (Latour 2004: 247) and not simply espouse oppositional and negative criticisms. In other words, good critique needs to be affirmative and experimental 
and not simply an unveiling of power relations and what is wrong. Critique needs to be working through practices and not simply about them. This critique of critique as simply negative might be said to apply to much of the critical discussion of competence-based education.

Responding to climate change deniers and conspiracy theories surrounding the destruction of the twin towers in New York, Latour (2004) posed the question polemically, 'why has critique run out of steam?' It is a question much of his work since has sought to address, and that educational researchers might well ponder. Many educational critiques are rooted in liberal progressive, feminist, post-structural, post-colonial or neo-Marxist orientations. Educational and social researchers have worked very hard to reveal the machinations of capitalism, interrupt knowledge that is commonly described as received thinking or supporting false inevitabilities, or expose the power flows that are claimed to produce domination or limit subjectivities. These critiques are circulated enthusiastically in scholarly journals, in dialogues that perhaps are becoming what Flinders (2013) suggests are selfreferential and self-reverential. Yet educational practices have more or less successfully avoided changing the existing reproductions of power and inequalities in education despite these critiques. Competency-based education is enjoying renewals in the US, UK, and Europe and inequalities continue to be supported through educational practices.

In all of this, there has been little reflection on the practices of critique being enacted in educational scholarship. The more common academic reaction to lack of policy response tends to be further hermeneutic suspicion, and continued analysis of how power is exercised to exclude the voices and possibilities of critique and progressive forms of change. Here certain forms of critique might be argued inadvertently to be reproducing that which they 
critique. Given this, we might well heed Latour's argument that critique has run out of steam in education as elsewhere.

Latour (2004) is never afraid to be controversial and starts his discussion by drawing an analogy between the logic of some forms of critique provided by researchers, including himself, and those offered by conspiracy theorists. In particular, he is commenting on the way the critic can unveil the truth to others by identifying the agents through which power is exercised behind their backs.

[W] hat's the real difference between conspiracists and a popularised, that is a teachable version of social critique inspired for instance by a too quick reading of... Pierre Bourdieu? In both cases, you have to learn to become suspicious of everything people say because 'of course we all know' that they live in the thralls of a complete illusion on their real motives. Then, after disbelief has struck and an explanation is requested for what is really going on, in both cases again, it is the same appeal to powerful agents hidden in the dark acting always consistently, continuously, relentlessly. Of course, we in the academy like to use more elevated causes - society, discourse, knowledge-slashpower, fields of forces, empires, capitalism - while conspiracists like to portray a miserable bunch of greedy people with dark intents, but I find something troublingly similar in the structure of the explanation. ...What if explanations resorting automatically to power, society, discourse had outlived their usefulness?

(Latour 2004 p228-9)

Here, the logic of critique is about taking apart, separating out and unveiling what lies behind actors to explain their position and actions. It is only the critics who can see this, whether 
they are social scientists or conspiracy theorists. Latour identifies a certain pattern to in the conventional practices of social critique.

This time it is the poor bloke, again taken aback, whose behavior is now 'explained' by the powerful effects of indisputable matters of fact: 'You, ordinary fetishists, believe you are free but, in reality, you are acted on by forces you are not conscious of. Look at them, look, you blind idiot' (and here you insert whichever pet facts the social scientists fancy to work with, taking them from economic infrastructure, fields of discourse, social domination, race, class, and gender, maybe throwing in some neurobiology, evolutionary psychology, whatever, provided they act as indisputable facts whose origin, fabrication, mode of development are left unexamined). (Latour 2004 p238)

For Latour, these social substitutes do not explain but themselves need exploring, as the social alone cannot be taken as foundational. Thus the uptake of theory as an explanatory framework to be applied to data, to make sense of phenomenon, is for Latour nonsensical. Yet it is arguable that this is what much of the critique of competence-based education, including that drawing upon Foucault precisely does.

Latour is arguing that explanations relying upon taken for granted social categories substitute the invisible and hidden for the visible. As such, they produce a determination of practices that do not reside with the actors themselves, and indeed assume a priori who the actors are. The politics emerging from this form of social explanatory critique is limited, a commentary on how most actors are dupes of some order that is beyond them. It is the social critic that is always right and able to see what is invisible to others. 
For Latour, the limitation of this form of critique arises fundamentally from the separation of a specifically social domain from nature and the material. This both limits critique and the identification of actors to enact alternatives. His argument is that sociology has two possibilities, depending upon etymology. One is to become the science of society, establishing matters of fact about the world based upon a separation from the natural and material, which entail the closing down of controversies. The second is to trace associations of multiple materials in the enactment of matters of concern, wherein controversies are kept open, conditional. He argues that the former has predominated at the expense of the latter, because of the modern logic of separation and the centring of the human. As a result, there is a reification of the social as an entirely distinct domain from the natural. Thus 'critical sociologists have underestimated the difficulty of doing politics by insisting that the social consists of just a few types of participants' (Latour 2005: 250). The social is taken to be 'constructed' from human intention and agency (the subjective), while nature is taken to be inert matter (objective), subject to human action. In critiques based upon this separation, the social is used to explain the social, trapping criticism in a logic where what is used to explain - e.g. social structures, capitalism, neo-liberalism - precisely needs explanation themselves.

Latour argues that social explanation relies upon a substitution of the phenomenon by some other social substance, usually an abstraction. For instance, in examining the phenomenon of educational inequality, scientists of the social might put forward capitalism, class, gender, race as explanations. These substitute for the phenomenon themselves, working behind their backs. In the case of the critique of competence-based education using Foucault, discipline becomes a substitute for competence. Critique takes apart, unveils and explains phenomena regardless of what the actors say or do themselves. In contrast to a science of society, Latour argues for a sociology of associations focusing on traceable attachments, whatever and 
wherever they might be, deconstructing the separation of society and nature. Thus, his argument for different critical practices and their associated politics.

The separation of society and nature is fabricated by a range of other practices of purification and naturalisation, between, for instance, matter and signification, practice and theory, object and subject, intervention and representation (Edwards 2012). These separations result in and from particular practices of critique, wherein things are separated out as objects with properties, the relationships between which then have to be explained. For Latour (2004), these practices fabricate 'matters of fact' around and over which develop particular practices of critique. Matters of fact assume and enact an epistemology representation, of separation untangled from the material practices through which they are fabricated or enacted. Critique becomes merely a matter of the conflict of represented facts - 'she says, he says...' - the taking apart of the object and a debate over truth, evidence and facts. To establish matters of fact entails a closure of debate, already a political practice. However, 'reality is not defined by matters of fact. Matters of fact are not all that is given in experience. Matters of fact are only very partial and, I would argue, very polemical, very political renderings of matters of concern and only a subset of what could also be called states of affairs' (Latour 2004 p232, emphasis in original).

It might be argued that this is a position with which many social critics would agree. Much critique is about unveiling matters of fact as ideological mystification, fetishes, forms of alienation, disciplinary, etc., in order to make them controversial and political. Social critiques regularly argue that what is taken to be real is actually contingent. On this basis, what is so different or controversial about Latour's position? The answer lies in the continuation of the logic of separation and unveiling in social critical approaches, wherein 
there is one world, but many interpretations. In other words, because of the assumptions with which they work, the social critic is caught within a logic of arguing over matters of fact, even as they critique the given facts.

By contrast, for Latour in particular, realities cannot be stabilised through separation and the closure of controversies to establish matters of fact. Realities are experimentally enacted through things, which are attached, gathered and negotiated as 'matters of concern', through open controversies. Here the real is not contrasted with the socially constructed, but is taken seriously as fabricated. Matters of concern are an attaching, gathering, for instance, matter and meaning, objects and subjects, nature and society, non-human and human in their enactments. Here the practices of critique are about what can be gathered or fabricated as concerns, where that attached is not simply human, and the relationships and their effects can be traced. Thus, for instance, critique, rather than exploring (human) public participation in political issues, engages in experimentation in the enactment of publics through the gathering of materials and humans (Whatmore and Landstrom 2011). In the very methods of critique there is active political engagement, but one where the political collective is not simply human. It is perhaps notable here that Foucault himself combined his writing on topics like madness and discipline with active political engagement on topics, whereas many of the critiques drawing upon his work are separated from the multiple possible forms of political activity. The later uses concepts from Foucault to try to explain phenomena, whereas his written work was part of his intervention in the issues he explored.

\section{Critical practices and competence-based education}

The above discussion points to some of the history of critiques of competence-based education and an argument as to how they have had so little effect. It suggests the need for 
different practices of critique in relation to competence-based education in particular and in relation to issues more generally, as matters of concern. Such an undertaking can be baffling because of its unfamiliarity and also the uncertainty it introduces into established practices. For Latour, a different form of critique requires us to follow the ways in which entities are attached in ways that produce traceable actions. This entails gathering and adding and not simply taking apart. It entails a refusal of separation and explanatory hierarchy. This is the reason Latour (2005) argues for critical practices of attachment and experimentation, gathering a thing as a matter of concern rather than taking apart an object to establish a matter of fact.

The critic is not the one who debunks, but the one who assembles. The critic is not the one who lifts the rugs from under the feet of the naive believers, but the one who offers the participants arenas in which to gather. The critic is not the one who alternates haphazardly between antifetishism and positivism like the drunk iconoclast drawn by Goya, but the one for whom, if something is constructed, then it means it is fragile, and thus in great need of care and caution. (Latour 2004 p246)

There is an openness in such practices that some might find unsatisfactory. To offer critique might be argued to make a stand, to have a standpoint, to emancipate ourselves from something. For Latour, the danger of such enactments is that they can result in too hasty separations and closures, turning matters of concern into matters of fact under hegemonic social explanations that reproduce rather than transform inequalities. His empirical approach is focused on keeping open the controversies, or at least slowing down the process of resolving controversies about that of which the world is made. He urges researchers to resist available explanatory categories and examine more closely the controversies and 
uncertainties about how resources and agency are distributed, the kinds of agencies that are enacted in different formations, and the ways that actors contextualise one another. Most important, Latour's critical attention is to the mechanisms of these relations that act to stabilise and 'blackbox' particular categories, assumptions, hierarchies and practices. The effort of analysis, for Latour (2005: 261), should be 'to highlight the stabilising mechanisms so that the premature transformation of matters of concern into matters of fact is counteracted'. The question then for educational researchers, is what in our practices of critique do we attach or gather and how can we attach better to have impact? In relation to competence-based education, we might ask what alliances are possible to expand competence into a different form of experimental practice, what people, discourses and objects can be aligned to enact interventions for different forms of vocational education? How to attach critique to the desired aims of competence-based education in order that the concerns are never closed from engagement? This is not a position of programmatic alternatives to competence-based education or simple opposition, but embraces with the materialities of how things are ordered. It is a politics of attachment and experimentation, of materialities and intensities, of the human and non-human. How to do this is less clear, as Latour himself maintains, his argument at high levels of abstraction.

Gathering alternative collectives in enacting competence-based education as a matter of concern entails experimentation rather than explanation. The latter forms of critique impose normative categories and ideologies on phenomena without sufficient attention being given to their specificities and material dynamics. Tracing the ways in which competence-based education has been enacted and black-boxed as a matter of fact, both despite and may be because of the forms of critique to which it is subject may be part of such critical practices. This requires different forms of experimentation beyond conventional academic critiques. It 
possibly means putting aside the writing of articles such as this and seeking different forms of intervention and gathering...

\section{Bibliography}

Ashworth,P. and Saxton,J. (1990) 'On 'Competence", Journal of Further and Higher

Education 14, 2

Edwards, R. (2012) 'Theory matters: representation and experimentation in education', Education Philosophy and Theory, 44, 5: 522-34.

Edwards, R. and Fenwick, T. (2015) 'Critique and Politics: A sociomaterialist intervention', Educational Philosophy and Theory, 47, 13-14: 1385-1404.

Edwards, R. and Usher, R. (2004) 'Disciplining the subject: the power of competence', Studies in the Education of Adults 26.

Field,J. (1990) 'Competency and the pedagogy of labour', Studies in the Education of Adults 23,1

Flinders, M. (2013). The politics of engaged scholarship: impact, relevance and imagination. Policy \& Politics 41 (4), 621-42.

Foucault,M. (1979) Discipline and Punish: The Birth of the Prison ,Harmondsworth Penguin Foucault,M. (1980) Power/Knowledge;Selected Interviews and Other Writings 1972-77, Brighton Harvester Press

Foucault,M. (1981) The History of Sexuality Volume 1 An Introduction, Harmondsworth Penguin

Hyland,T. (1992) 'Expertise and Competence in Further and Adult Education', in British Journal of In-service Education 18, 1: pp23-8

Jessup,G. (1991) Outcomes: NVQs and the emerging model of education and training, London Falmer Press 
Latour, B. (2004). Why has critique run out of steam? From matters of fact to matters of concern. Critical Inquiry 30: 225-48.

Latour, B. (2005). Reassembling the social. Oxford: Oxford University Press.

NCVQ (1988) The NVQ Criteria and Related Guidance, London NCVQ

Raggatt,P. (1991) 'Quality Assurance and NVQs', in Raggatt,P. and Unwin,L. (Eds) Change and Intervention: Vocational Education and Training, London Falmer Press

Whatmore, S and Landstrom, C. (2011) Flood apprentices: an exercise in making things

public. Economy \& Society 40 (4), 582-610.

Wolf,A and Mitchell,L. (1991) 'Understanding the Place of Knowledge and Understanding in a Competence Based Approach', in Fennell,E. (Ed) Development of Assessable Standards for National Certification HMSO pp25-9 